\title{
“OH MY GOD! BUY IT!” A Multimodal Discourse Anal- ysis of the Discursive Strategies Used by Chinese Ecom- merce Live-streamer Austin Li
}

\author{
Haiyan Huang, Jan Blommaert and Ellen Van Praet
}

\begin{abstract}
Ecommerce livestreaming, also known as live commerce or social commerce, has taken off over the past two years in East Asia and is showing the tendency of going global. Intrigued by the phenomenal success of ecommerce livestream, we concentrate on analyzing the most prominent and illustrative example of Chinese ecommerce live-streamer Austin Li. Through this individual case study, we aim to investigate discursive strategies employed in ecommerce livestreaming and reveal resources specific to this new media genre. Guided by multimodal discourse analysis, our research first accommodates the socio-economic context of Li's success to warrant social situatedness in interpreting data. After that we move into analyzing his discourse employed in livestreaming. Research findings suggest that in attention economy, Li strategically utilizes his male gender as a resource in trying on lipsticks for female customers. His discourse in multiple modes serves to build consumer trust and propagate products. An in-depth analysis of his discursive strategies indicates that, ecommerce livestreaming as a new form of advertising not only shares commonalities with traditional advertisement discourse but also embodies affordances that are specific to livestreaming platforms. To be more specific, livestreaming is featured with delimitation of time, real-time interactivity, and video-aided communication. These affordances enable Li to adopt more interactive and personalized persuasive discourse than conventional advertisements.
\end{abstract}

Keywords: ecommerce livestreaming, live commerce, social commerce, social media influencer, multimodal discourse analysis (MDA)

\section{Ecommerce Livestreaming}

Ecommerce livestreaming, also known as live commerce or social commerce, has taken off over the past two years. In 2019, revenue generated by ecommerce livestreaming reached 433.8 billion Chinese Yuan ( $\$ 61.4$ billion) and the figure is projected to double in 2020 (iiMedia Research, 2020a). There are now multiple platforms on which ecommerce livestreaming is available, mainly include Taobao - Alibaba's premier C2C ecommerce marketplace in China, Mugujie, and Kuaishou. Take Taobao, which is the most well-developed and occupies the largest market share, for example, ecommerce livestreaming generated over 100 billion Chinese Yuan ( $\$ 14$ billion) in its transactions in 2018, and the revenue exceeded 2000 billion Chinese Yuan ( $\$ 28$ billion) in 2019 (CBNData, 2020). A survey conducted by iiMedia Research (2020b) indicates that in China, there are now roughly 20,000 ecommerce live-streamers and more multi-channel networks (MCNs) are joining to train professional hosts (Topklout, 2020). Such live 
ecommerce hype is going global too. Alibaba has brought the practice to Russia and other Asian countries, such as Thailand, Japan and South Korea. In the United States and Europe, Amazon, Wayfair, Monki, and luxury brand Luis Vuitton have noticed the power of live commerce and have started to use this new media genre to attract potential customer.

Current live ecommerce comprises two forms. The first is livestreaming on ecommerce platforms, such as Taobao (Alibaba's premier C2C ecommerce marketplace in China), and Mogujie on which live-streamers produce contents to propogate products. The second type occurs on content platforms such as Douyin and Kuaishou which collaborate with third party ecommerce platforms. Regardless of which form it takes, ecommerce livestreaming involves five parties, namely, producers (brands), platforms, MCNs, live-streamers and audiences. For professional live-streamers, such as Viya Huang, Austin Li and Xinba, they work with MCNs which negotiates with producers and then choose which products to be broadcast. Live-streamers then promote the products through livestreaming. When broadcasting, streamers have two devices at hand. The main equipment is the webcam in front of them and displays the livestreaming. A second mobile device is deployed nearby and allows them to read the barrages sent by audiences. For audience, they are able to watch sessions on their mobile devices, such as smart phones or tablets, and send their opinions to the platform and platforms. The messages (barrages) sent are visible on screen both to live-streamers and to other peer audiences. On the top of livestreaming page is the personal accounts of streamers, as shown in Image 2 below. Audience can follow them by clicking on the button. On the left bottom is a package of links of products promoted. Audience can buy the product just by clicking the link that will direct them to the shopping page, as shown in Image 3 below. Audiences can also choose to hide all these sub-sections just by tapping the center of their screens.

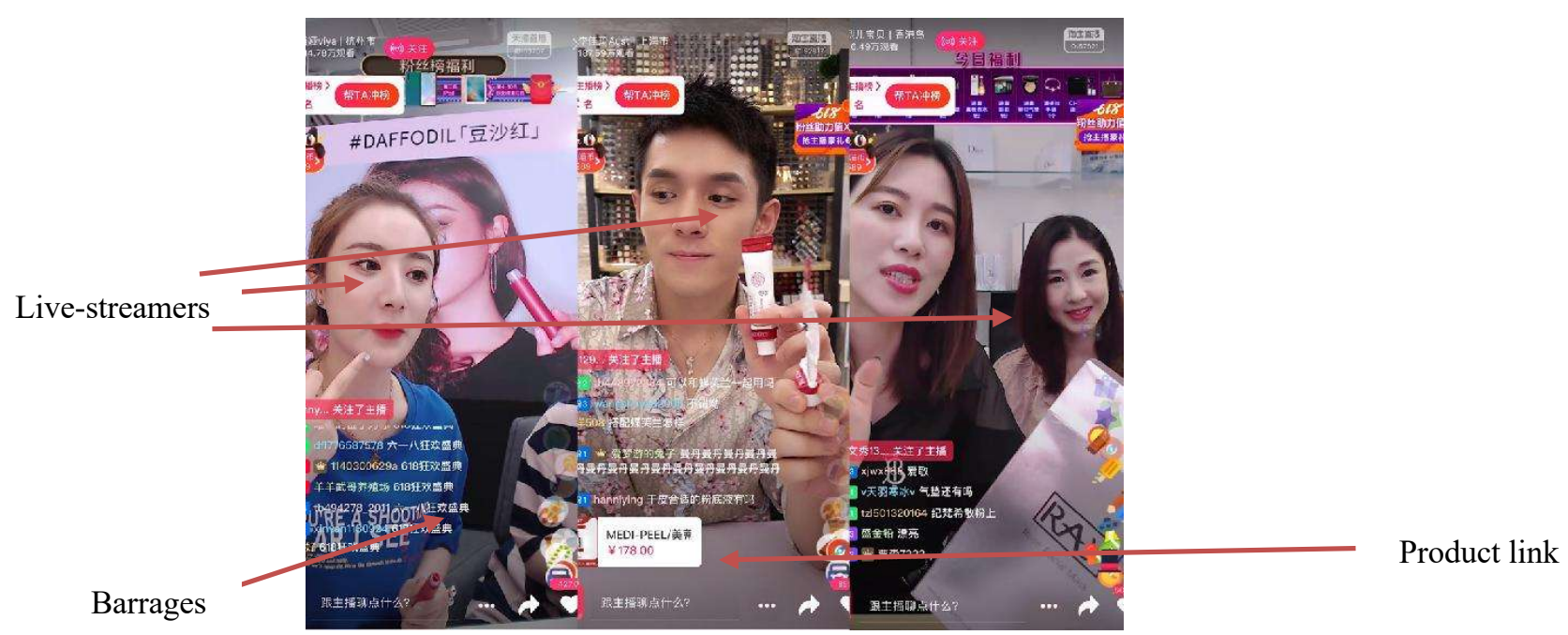

Image 1: An overview of Taobao livestreaming on users' screen 


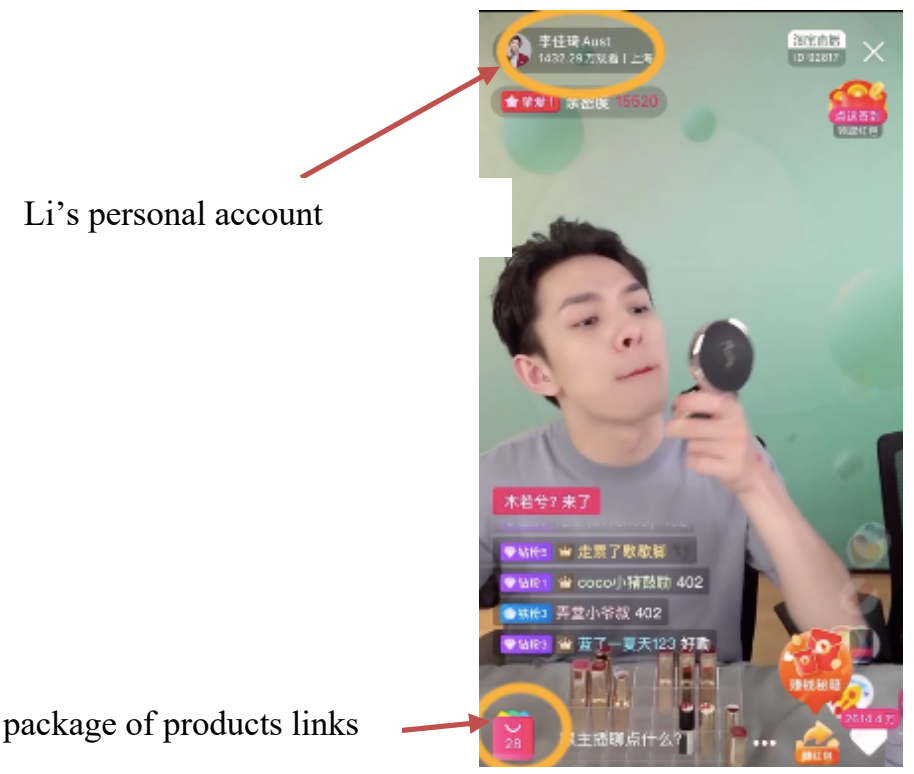

Image 2: An overview of livestreaming session screen

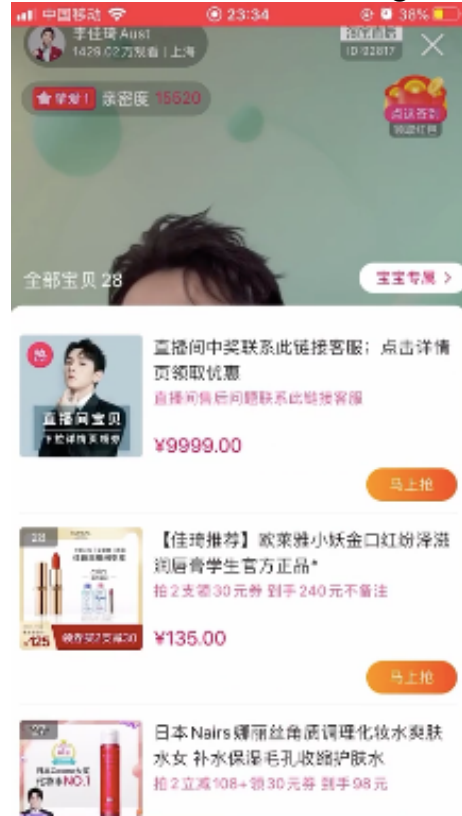

Image 3: An overview of the screen after clicking product links

Amazed with the phenomenal success of live commerce and intrigued by this latest developed media genre and, we aim to investigate discursive strategies employed in ecommerce livestreaming and reveal resources specific to this new media genre. To fulfill our goals, we take Multimodal Discourse Analysis (MDA) as the research approach to look at an illustrative case-Austin Li, a Chinese ecommerce live-streamer 
who is known as "Lipstick King". Specifically, we aim to answer the following research questions:

- How does Li position himself as a male live-streamer who promotes lipsticks?

- How the characteristics of ecommerce livestreaming platforms impact Li's discourse?

- What discursive strategies does Li employ in his livestreaming?

- What are the discursive differences between Li's livestreaming and traditional advertisements

\section{Methodology}

\subsection{Multimodal Discourse Analysis}

We rely on multimodal critical discourse analysis (MDA) as the research framework. According to Blommaert (2005), discourse comprises "a general mode of semiosis, i.e., meaningful symbolic behavior" (p. 2). Traditionally, discourse analysis heavily attends to linguistic resources (Fairclough, 2001; Wodak, 1989; Kress \& Van Leeuwen, 1996). However, the advent and wide application of digital technologies have diversified the modes of discourse, and expanded the subject of discourse analysis from texts to images, gazes, facial expressions and spatial positioning of people (or objects) inside the image, composition and among others (Kress, 2010; Jewitt, 2009). Inspired by theories of systematic functional linguistic and social semiotic (Halliday, 1978 \& 1994), traditional discourse researchers believe that non-linguistic modes also plays fundamental role in rendering social meanings (Kress \& van Leeuwen, 2001; van Leeuwen, 2005) and thus appeal for MDA in addressing digital texts in which two or more semiotic systems are present. The aim of MDA is to understand the how multiple modes interact with one another to make complete meanings. Advocates of MDA hold that this method provides "more comprehensive and inclusive inquiries, analyses, and representations that can be socially, culturally and politically transformative" (Literat et al., 2017, p.5). MDA has been applied in film, music, advertisements and new media studies where audio, visual and linguistic representations are intertwined (e.g., Gill, 2015; Brady, 2015; Baykal, 2016). Jewitt (2009) summarizes that there three different approaches when conducting multimodal analysis. The first one is social semiotic approach which emphasizes the role of choices in rendering meanings. The second one is MDA and focuses on meaning interpretations. The subtle difference between social semiotic approach and MDA is that the former attaches more importance of "sign-maker" (ibid, p.36) than the latter. The last approach comprises multimodal interactional analysis which "addresses a dimension of the social semiotic that conventional multimodal analysis does not seem to commonly address and focuses on how multimodal texts are interfaced with and mediated by people" (ibid, p.33). In this study, we choose MDA as the research framework. 


\subsection{Data Collection and Transcription}

Our study focuses on the most prominent and illustrative example of Chinese ecommerce live- streamer Austin $\mathrm{Li}$ as the research subject. Such a method of drawing on individual case study enables scholars to have in-depth understanding of social behavior (Meyer, 2001) and proves constructive in researching exploratory topics (Frey, Botan, \& Kreps, 1999). In microcelebrities studies, researchers frequently relies on this method, such as Gamson's (2011) analysis of Marlene Dietrich, Marwick's (2013) analysis of Adam Jackson, Jerslev's (2016) analysis of Zoella and Li's (2019) analysis on Papi Jiang.

Our data comprises Li's livestreaming sessions online. Considering Li became famous by broadcasting lipsticks, we limit our data to his livestreaming merely about lipsticks. In collecting data, we found that neither Taobao nor Li's team releases have fully recorded or publicized his livestreamings about lipsticks. As an alternative, we choose to use data on Bilibili website since it possesses more abundant video clips about Li's livestreaming than other video platforms, such as Youtube, Tencent or Aiqiyi. The video clips on Bilibili are recorded by audiences of the time when they were watching the livestreaming sessions. We then input key words “Austin Li Lipstick” (李佳琦口 红) in the searching bar and search results are rather miscellaneous, including clips of varying length and different people in camera. We then further set more specific rules and only choose those that are recordings of Li's livestreaming sessions and that are more than 5 minutes at least to ensure context of the livestreaming is fully demonstrated. In this way, we have more than 400 minutes of data that fulfills our criteria.

One challenge of MDA is data transcription (Kress, 2010; Recktenwald, 2017). In multimodal texts, multiple modes may impact data interpretation and researchers thus find it difficult to decide what should(not) be transcribed. Kress (2010) suggests scholars to understand their research purposes before transcribing data. As our study aims to analyze discursive strategies Li employs in livestreaming, we incorporate elements that contribute to persuasiveness in the data transcribed. Following the suggestion by Recktenwald (2017 \& 2018), we adopts the multi-column transcription scheme as it allows us to present oral text and images in a concise and synchronized manner. In transcribing, we mainly follow the transcription codes followed by Dressler and Kreuz (2000).

\section{Data Analysis And Findings}

Before delving into the discursive strategies Li employs in broadcasting lipsticks, it is critical to be aware of the socio-economic context in which Li's success materializes. Such context consists of two levels - that of the society and of the ecommerce livestreaming platforms. Only when we situate the analysis within these backdrop shall we be able to draw accurate data interpretations and be aware of the connections of this media genre and discursive patterns that emerge.

We are in the age of participatory web in which numerous individual netizens contribute users generated contents (Walther \& Jang, 2012). Such abundant information online on one hand diversifies our daily life while on the hand other distracts us. Those 
who enjoy the most attention accumulate online fame and establish high online status. Attention thus is a rather valuable asset for microcelebrities. When analyzing Li's case, we repeatedly reflect on his success against this background and here propose that trying on lipsticks as a male streamer - a counterintuitive conduct, is capitalized on to attract audience's attention.

Besides attention economy, another distinct economic feature we shall point out here is network economy. The business mode of live ecommerce gives full play to networked economy. Ecommerce live-streamers have connections to millions of followers and audiences who are presented with literally numerous options in buying their desired items. Scholars (e.g., Sharma, Menard \& Mutchler, 2017) suggest that organizations have realized the potential of social capital, i.e., drawing on social networks to promote sales, and understood the importance of trust in network economy. When it comes to online transactions, trust comes at greater importance as consumers are presented with countless choices and conflicting information (Azam, Qiang, \& Sharif, 2013; Yoon \& Occena, 2015; Tikhomirova \& Shuai, 2019). In Li's livestreamings, he employs a myriad of strategies to establish and further enhance his trustworthiness and credibility among his audiences, which serves as a very important antecedent to his successful livestreaming career.

\subsection{Gender as Resource}

Austin $\mathrm{Li}$ is a professional ecommerce live-streamer on Taobao. He started to broadcast on Taobao from 2017 and ever since, he has attracted millions of followers on his livestreaming channels. On November 11th 2018, which is known as Double Eleven Shopping Festival, he set the record of selling over 150,000 lipsticks within five minutes. According to his own accounts, Li now possesses over 50 million followers across his social media, including Taobao livestreaming platform, Douyin, and Weibo (iFeng Finance, 2019).

At first glance, Li's phenomenal success comes unexpected given that he-a male broadcaster, promoting and trying on lipsticks, is against social norms. In social media 2.0 era when individuals are presented with all types of contents and smart devices, attention has become a valuable asset (Tufekci, 2013; Romaniuk \& Nguyen, 2017). Researchers through empirical studies found that attention impacts product preference and brand consideration (Chandon, et al., 2009; Janiszewski, Kuo \& Tavassoli, 2013). Marwick (2015) suggests that microcelebrities grasped a range of techniques to appeal for attention, including traditional attention-seeking strategies employed by consumer brands, and behaviors that do not fit "the norms of mass culture" (p.138). In Li's case under scrutiny, $\mathrm{Li}$, instead of seeing his gender as an disadvantage, strategically uses it a resource to conduct socially abnormal action - male putting on lipsticks. His counterintuitive behavior helps attract wide-scale attention from users and makes his first step towards a successful ecommerce livestreamer.

\subsection{Constructing Trust}

Presently the most widely accepted definition of trust is "the willingness of a party to be vulnerable to the actions of another party based on the expectation that the other will perform a particular action important to trustor, irrespective of the ability to monitor or control the other party" (Mayer, Davis, \& Schoorman, 1995, p. 712). Companies 
enjoying high level of credibility find their customers are more receptive to incoming promotional information and products (Fuoli \& Hart, 2018). Such trust is of particular important resource but also difficult to attain for e-retailers. Potential consumers of online transactions often are overwhelmed and intimidated by false information and shoddy products provided on ecommerce websites (Yoon, 2002; Hajli et al., 2017).

Gibson and Manuel (2003) proposed that the key means to construct trust is through communication. This view is echoed by sociolinguists who hold the view that organizations that aspire to construct consumer trust, extensively capitalize on linguistic and other semiotic resources to promote a sense of belonging and a congenial relationship with their customers (Sinclair, 2004). Prior research suggest that trust can be discursively constructed in three dimensions - competence, benevolence and integrity (Gibson \& Manuel, 2003). Competence concerns with individuals or organizations' expertise and professionalism in their fields. Benevolence refers to the extent to which altruism is shown and integrity is related to the qualities of being candid, honest and sincere. In analyzing the data we collected, we noticed that Li strategically constructs audiences' trust by demonstrating his quality of integrity.

Integrity. The salient characteristics of Li's livestreaming is that he directly criticizes the products he tries on. In this way, he manages to create the impression that he is a candid and honest person and that he aligns himself with audiences, rather than flattering products manufacturers. This strategy lends him credibility in the highly networked economy in China. The following excerpt is an example.

\begin{tabular}{l} 
\# 1 Extract \\
\hline \multicolumn{1}{|c|}{ Spoken Texts } \\
\hline 1 Li: What is this? \\
2 Fu: This (..) The money for this is the sum of ten \\
these here (pointing at lipsticks). \\
\hline 3 Li: Hermes bag? A lipstick bag?
\end{tabular}




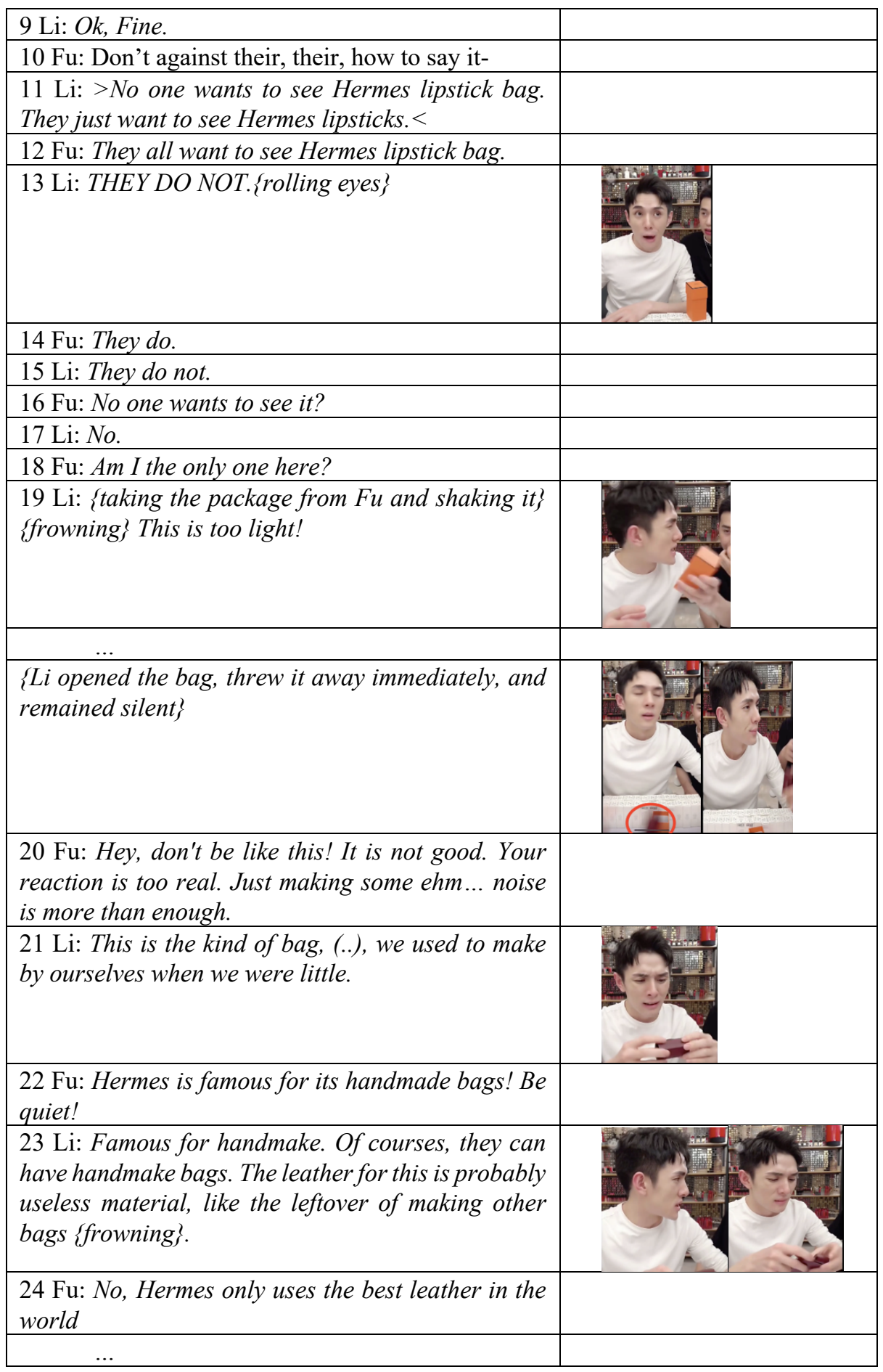




\begin{tabular}{|l|}
\hline $25 \mathrm{Li}$ : How much is it? \\
\hline 26 Fu: More than 4000 yuan. \\
\hline ... \\
\hline 27 Li: This is really (..) \{rolling eyes\}. With 4000 \\
yuan can do a lot of things. Really, I, I, I can never \\
get the point of this bag for my whole life. Maybe I \\
am not that fashionable, not that fancy. Oh, my gosh. \\
$\begin{array}{l}\text { It is really easy to make money these days \{raising } \\
\text { eyebrows, shaking head\}. }\end{array}$ \\
\hline
\end{tabular}

Two themes in this argument stand out. First, through linguistic forms and bodily language, $\mathrm{Li}$ constantly displayed his disinterest and disappointments with the bag despite the fact it is made by the world famous bag company-Hermes. Conventionally, Hermes is well-known as a luxury brand that is particularly specialized in making quality and classic bags by handmade. These positive qualities associated with Hermes bag, however were all rejected by Li here. Rather, he explicitly stated that audiences are not interested in this lipstick bag and the bag is "too light", which renders the impression of low-quality here. He further showed his contempt by guessing the material for the tiny lipstick bag is made of "leftover" material of other Hermes bags. These dismissals form a sharp contrast with what Fu said afterwards in unit 24 - "Hermes only uses the best leather in the world". His criticisms contribute to establishing his personality as honest. Besides these linguistic resources used, $\mathrm{Li}$ also resorted to a set of nonverbal signs, such as rolling eyes, sighing, raising eyebrows, and shaking head, to indicate his disagreement with Fu and disbelief on the price of Hermes lipstick bag. These bodily movements underscore his true feelings and opinions that are expressed through linguistic forms. In this way, his disinterest is strengthened and highlighted through a combination of linguistic and bodily semiosis. Second, throughout the conversation, he clearly aligns himself with audiences. Previous studies have found that such alignment strategies directly enhances trust and play an indirect role in fostering perceived credibility. Corporations and individuals strategically draw on stances resources to construct identities, legitimize behaviors and attain support (Fuoli, 2018; Hart, 2014; Bondi, 2016; Fuoli \& Paradis, 2014). As discussed before, live ecommerce involves multiple parties, including product producers, ecommerce platforms, live-streamers, MCNs, and audiences. Live-streamers make profits by charging commissions from the items they sell. It is clear that the more they sell, the more financial benefits that they will enjoy. Live-streamers thus are motivated to take a stance with capitalist companies, from the point of financial benefits. However, the conversation here proves this prediction is not necessarily true. Rather than identifying himself with Hermes, Li firmly took the stance with his audiences. For instance, when Fu asked if anyone was interested in seeing the bag, Li directly spoke on behalf of the audience that they did not want to see the bag (units 13, 15 \& 17). In the end of the excerpt, he suggested that 4,000 yuan for a Hermes bag was overpriced and warned people that with that amount of money "can do a lot of things", which may dissuade them from buying the overpriced bag. The remark "Oh my gosh! It is really easy to make money these days!" (unit 27) obviously targeted at Hermes, an example of capitalist corporation, and accused the unfairness of how easy it is for capitalists to earn money from the mass. In this way, he aggrieved the greediness 
of the capitalism and sympathized the public who are exploited. This stance-taking act here is used as a resources to enhance consumer trust, which plays a fundamental role in maximizing persuasiveness.

\subsection{Employing Discursive Strategies to Promote Products}

Live ecommerce is a type of advertisement that is delivered on highly digitalized livestreaming platforms. Discursive strategies used for persuading audiences thus may overlap with those found in traditional advertisement discourse while at the same time, embodies characteristics that are specific to livestreaming.

Exclamations. Using exclamations, such as "God", "Oh my god”, “Oh, my gosh", "Jesus Christ", are frequently used in advertisement to reveal strong emotions and indicated amazement and surprise (Syakur \& Sukri, 2018). As we see in almost Li's all livestreaming, he very frequently, if not always, uses exclamation expressions mentioned above. His catchphrases, "OH MY GOD” , "OH MY GOSH” have become his personal identifiers and it is reported that his team has already trademarked the exclamation expression of "OH MY GOD". Below is one typical instance of extensive usages of exclamations.

\begin{tabular}{|c|c|}
\hline Spoken Texts & Livestreaming Images \\
\hline 1 Let me tell you, what can I say? & \\
\hline $\begin{array}{l}2 \text { Only... Not oh my god, what to say? } \\
\text { Oh my mom! I have to say Oh my } \\
\text { mother! }\end{array}$ & \\
\hline $\begin{array}{l}3 \text { This color is just <extremely beauti- } \\
\text { ful>. Pretties, go to the mall tomorrow } \\
\text { and buy one. Is it available online, Song } \\
\text { Kang?\{looking at his team member\} }\end{array}$ & \\
\hline$\ldots$ & \\
\hline $4 O H M Y M O M !$ & \\
\hline $\begin{array}{l}5 \text { This color, my mom, oh no, oh my } \\
\text { mother! }\end{array}$ & \\
\hline $6 I(.)$, oh my mom. & \\
\hline $\begin{array}{l}7 \text { It is REALLY TOO PRETTY. Lipstick } \\
330\end{array}$ & \\
\hline$\ldots$ & \\
\hline
\end{tabular}




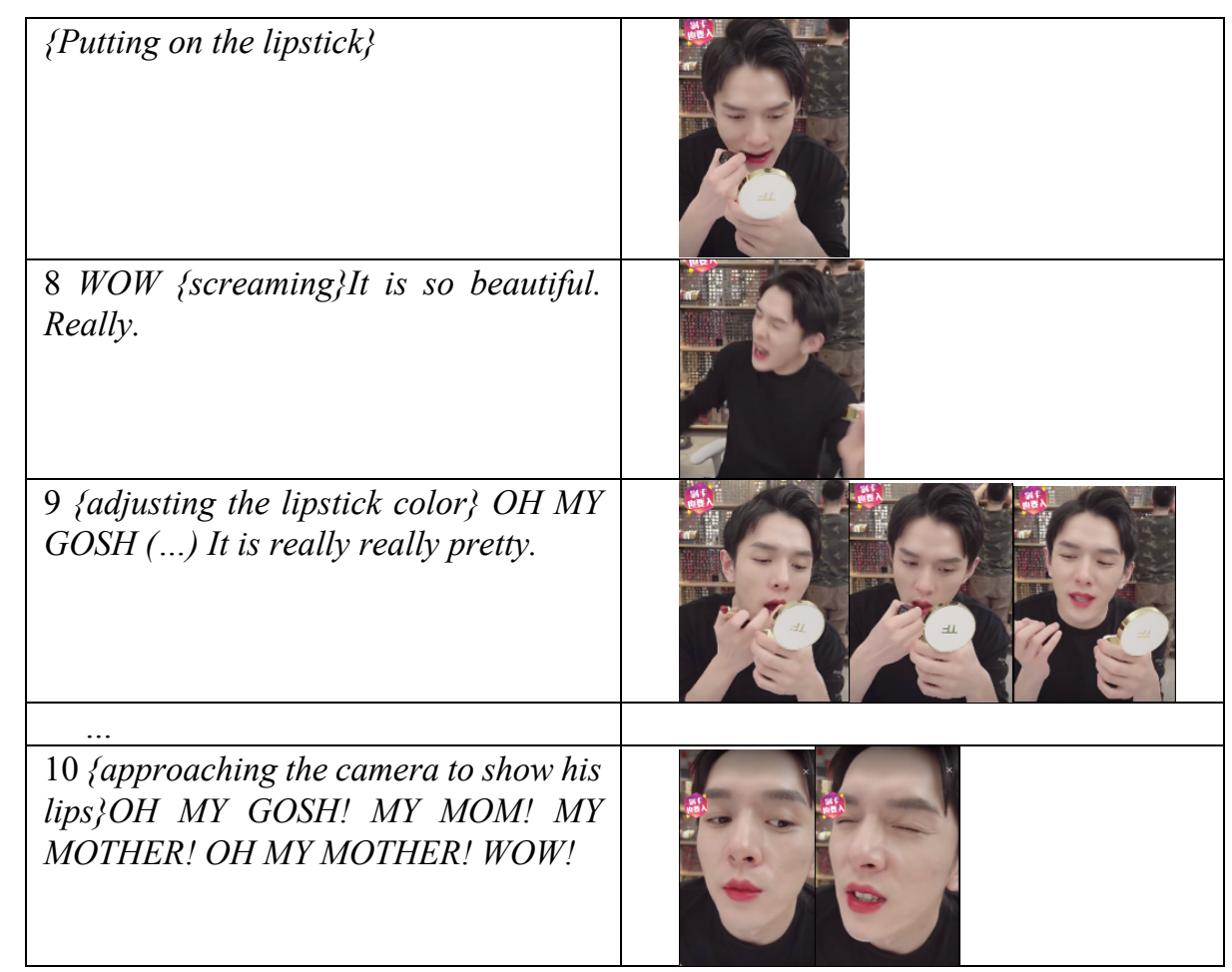

This review occurred in a livestreaming when Li was trying on Guerlain lipstick 330. After putting it on, he used strong exclamation words and expressions, "WOW", "OH, MY GOD”, “OH MY GOSH”, “OH MY MOM”, "OH MY MOTHER” repeatedly to show how surprising and astound he is with the lipstick. Moreover, instead of merely saying "OH MY GOSH", "OH MY GOD”- -his catchphrases, he explicitly remarked that English exclamations are not enough and thus suggested to use Chinese exclamations, "OH MY MOM" (wodiniangya), "OH MY MOTHER"(wodemaya), which are oral expressions frequently used to show strong emotions, such as surprise, happiness, astonishment, etc.. Li here expressed the need to use his first language - Chinese so that he would be able to show his emotional strength. Switching exclamations from English to Chinese plays an more effective role in communicating his emotion and views to audiences, who may find themselves emotionally mobilized by Li's discourse. His rising voice volumes (unit 8) and exaggerated facial expressions (units 3, 6, 8 and 10) here serve to strengthen the emotional power of his linguistic utterance.

Imperatives. Using imperative represents a typical grammatical features of advertisement discourse (Kaur, Arumugam \& Yunus, 2013; Labrador et al., 2014; Zjakic, Han $\&$ Liu, 2018). Previous studies suggest that advertisers often use imperatives to persuade consumers into taking actions and to establish close relationships with them (Kaur, Arumugam \& Yunus, 2013). The frequent imperatives Li uses are listed as followings. 
\#3 Extracts

\begin{tabular}{|l|l|}
\hline \multicolumn{1}{|c|}{ Spoken Texts } & Livestreaming Images \\
\hline 1 Buy it! Buy it! Buy it! & \\
\hline 2 Please buy it as soon as possible & \\
\hline 3 All girls, everybody, please go buy it right away! & \\
\hline 4 Put it in your shopping cart first, hurry up! & \\
\hline 5 You have to buy it! & \\
\hline 6 Bags, don't buy random ones. & \\
\hline
\end{tabular}

In describing how decent red the lipstick color is, he chose to compare it to "a graduate from Tsinghua University an Peking University", both of which are the top-notch higher education institutions in China. Graduates from these two universities are considered as intelligent, cultured, and high-level. Via this metaphor, Li not only vividly expressed how fancy and cultured the lipstick is but also demonstrated his creativitylinking a lipstick to top level higher education institutions. Such novelty and creativity can trigger audiences' interest and attract their attention. Previous studies suggest that novel metaphors are more effective for persuasive purposes (Ringrow, 2016; Sobrino, 2017). Below are other examples in which his resorts to different but creative metaphors.

\begin{tabular}{|c|c|}
\hline Spoken Texts & Livestreaming Image \\
\hline 1 OH MY MOTHER! & \\
\hline $\begin{array}{l}2 \text { With this color... Your lips are followers, } \\
\text { fully blooming peonies. }\end{array}$ & \\
\hline 3 Wow, I think this color (..). Really. & \\
\hline $\begin{array}{l}4 \text { Girls who have rich husbands, have to buy } \\
\text { it \{approached the camera to show his lips\}. }\end{array}$ & \\
\hline $\begin{array}{l}5 \text { If you go out with this lipstick on, your } \\
\text { husband, people definitely will think your } \\
\text { husband is rich. This is rich ladies' color. }\end{array}$ & \\
\hline
\end{tabular}

In this extract, Li compares lips with the flower peony, which is considered the national flower of China. Therefore the metaphor here connotes two-level significance. 
First, peonies by themselves are fresh, delicate and colorful. This metaphor thus maps out these positives onto the product advertised. This metaphorical function, i.e, presenting "what is being advertised in terms of other entities that that the characteristics which the advertisers want to associate to the product" (Hidalgo-Downing \& Kraljevic-Mujic, 2017 , p.324), has long been existing in advertisement discourse. Second, considered as a national flower of China, peony is closely associated with such qualities as beautiful, elegant and generous. Because of these social and cultural connotations associated with peonies, the metaphor used here indicates the semiotic meaning of having this lipstick; that is, it is a signifier of social status. This semiosis is corroborated by Li's explanations - "Girls who have rich husbands have to buy it. If you go out with this lipstick on, your husband, people definitely will think your husband is rich" (units 4 \& 5). In this way, having this lipstick in some way satisfies people's fantasy of having a rich life.

\begin{tabular}{|c|c|}
\hline Spoken Texts & $\begin{array}{l}\text { Livestreaming } \\
\text { Images }\end{array}$ \\
\hline $\begin{array}{l}1 \text { It is not sticky and the color applies evenly. It feels like putting } \\
\text { on a layer of smashed potato on lips, like a layer of flour on } \\
\text { lips. }\end{array}$ & \\
\hline 2 It is $<$ just so comfortable $>$. & \\
\hline $\begin{array}{l}3 \text { The feeling is like that something very softly touches your lips. } \\
\text { The feeling is, having melting chocolate on lips in summer. }\end{array}$ & \\
\hline 4 It is $<$ really so comfortable $>$. & Lixin \\
\hline
\end{tabular}

Li used several similes and metaphors in this extract to explain the feeling of using this lipstick. Very interestingly, he exclusively referred to food as vehicles - "smashed potato" (unit 1), "flour" (unit 1) and "melting chocolate" (unit 3). This pattern is in tandem with the trend that people in China, especially girls, who comprises the majority of Li's audiences (Sinolink Securities, 2019), are generally obsessed with food of all types, as indicated by the booming of food-related documentaries, including A Bite of China, Once Upon A Bite, A Bite of Guangdong, Giving Cycles, and amongst others. In this way, making comparisons with food that is familiar and imaginable to the audiences, Li successfully described the feeling of having the lipstick on in a very simple but expressive way. Such concretization plays a fundamental role in live ecommerce streaming given that the audiences are not able to try on products by themselves. Their expectations are greatly shaped through live-streamers' linguistic strategies. Previous studies (e.g., Tehseem \& Kalsoom, 2015) indicate that audiences are more reception to promotions when they are presented with metaphorical claims. 
Celebrity endorsement.

\#7 Extract

\begin{tabular}{|l|l|}
\hline \multicolumn{1}{|c|}{ Spoken Texts } & Livestreaming Image \\
\hline $\begin{array}{l}\text { 1 The first one I am gonna try for you is from Tom Ford, } \\
\text { color 69. }\end{array}$
\end{tabular}

Referring to celebrities represents another distinctive strategy in Li's persuasive discourse, as indicated in this extract. "Faye Wong" (unit 2) that appears in this extract, is recognized as a one of the most popular Chinese Cantonpop diva in Chinese diasporas and represents such qualities as "independent, unconventional, and contentious" (Fung, 2009, p. 252). Here, Li first associated this color with Faye Wong by assuming that Wong would like this color. He further nicknamed it "Faye Wong Color" to endorse this lipstick. By employing this strategy of celebrity endorsement, Li managed to attract audiences' attention and increase the product's credibility (Marwick, 2013). Those audience who aspire to mimic fancy and up-class lifestyle of the famous people will be intrigued with the lipstick and highly motivated to purchase it. Besides fulfilling this materialistic fantasy, possessing this lipstick also encourages its users to think they share the same qualities as Wong do, just by using the lipstick that Li thinks she would like. Lipsticks thus are synonymous to fancy life and ideal personal qualities.

Personalization. Although addressing millions of indeterminable viewers, Li draws on a myriad of discursive resources to personalize his audiences. Fairclough (2001) named this discourse strategy as synthetic personalization- "a compensatory tendency to give the impression of treating each of the people 'handled' en masse as an individual" (p.52). This strategy plays a critical role in building relations between advertisers and viewers, and appeal to the needs to potential customers. In Li's livestreaming, he mainly adopts four types of strategies, including using direct address, presupposing represented groups, contextualization, and interactivity. Previous researchers (Kaur, Arumugam \& Yunus, 2013; Labrador et al, 2014; Tehseem \& Kalsoom, 2015) have found that direct address with audience with second pronoun you is a widespread linguistic feature across advertisement discourse. Designating represented groups and specifying contexts are also reported in advertisement (Hu \&Luo, 2016). Live commerce, or called by social commerce, values the social media property and thus necessitates interactivity with audiences. Such interactive feature is a representation of participatory web and personalize audiences with different needs by giving them voice (Cao, 2019). Below are four illustrative examples to explain each strategy mentioned above.

Direct address.

\#8 Extract

\begin{tabular}{|l|l|} 
Spoken Texts & Livestreaming Image \\
\hline
\end{tabular}




\begin{tabular}{|c|c|}
\hline $\begin{array}{l}1 \text { The first one, } 316 . \text { This is a must buy. This color, no } \\
\text { matter how much you hate MAC, you have to buy this } \\
\text { one. }\end{array}$ & \\
\hline $\begin{array}{l}2 \text { No matter HOW MUCH you hate MAC the brand, if } \\
\text { you have to buy a lipstick, then there it is }\end{array}$ & \\
\hline $\begin{array}{l}3 \text { It is really good. A really good one. You have to spend } \\
170 \text { yuan to buy it no matter what. }\end{array}$ & \\
\hline $\begin{array}{l}4 \text { You have to save } 170 \text { yuan for MAC. MAC deserves to } \\
\text { ask for } 170 \text { yuan from you for this lipstick. }\end{array}$ & \\
\hline
\end{tabular}

In this extract, Li directly addressed to his audience with you for seven times although he had no clue who are the recipients. Using the second pronoun allows advertisers, $\mathrm{Li}$ in this case, to communicate with potential customers in a direct and personal manner, which contributes to a close relationship with audience and fostering trust. When directly addressing audiences, Li also looked at the screen to read barrages (image in unit 1) and this gesture can be considered as having eye contacts with audiences through the texts they sent. From the perspective of audiences, by being individually addressed to instead of an unknown member among millions of viewers, they tend to have the feeling that they are highly valued (Kaur, Arumugam \& Yunus, 2013).

Represented groups. \#9 Extract

\begin{tabular}{|l|}
\hline \multicolumn{1}{|c|}{ Spoken Texts } \\
\hline 1 If you a girl that dances, you have to buy it. If you a \\
girl who wears black clothes every day, you have to buy \\
it. \\
\hline 2 Why? Because it elevates your charisma to full score!
\end{tabular}

Li here identified two groups of audiences - girls who "dance" (unit 1) or "wear black clothes every day" (unit 1). Presupposing groups of different characteristics has two benefits. First, these personal cues encourages identifications from audiences. That is, those who identify themselves as girls who "dance" or "wear black clothes every day" might be mobilized into purchasing the lipstick (Aaker, Brumbaugh \& Grier 2000). The usage of direct address, i.e., second pronoun you, further promotes the impression that targeted groups are valued and understood well. Audience thus may respond to Li's understanding by buying the item. Second, his group specific suggestions save audiences' trouble in choosing suitable products. The example below further illustrates this point.

\begin{tabular}{|l|l|}
\hline \multicolumn{1}{|c|}{ S10 Extract } & \multicolumn{1}{|c|}{ Livestreaming Images } \\
\hline $\begin{array}{l}\text { 1 923, girls with fair skin have to buy it. If you } \\
\text { don't have fair skin, don't but it. }\end{array}$ \\
\hline
\end{tabular}




\begin{tabular}{|l|}
\hline 2 Because it requires makeups, ok? To wear \\
this color, you have to have makeups. You \\
HAVE TO HAVE makeup. \\
\hline $\begin{array}{l}\text { 3 Ifyour skin is more yellowish, then you really } \\
\text { have to have foundation. }\end{array}$ \\
\hline ... \\
\hline $\begin{array}{l}5 \text { And the color doesn't suit heavy makeups. } \\
\text { here, and eyebrows in the shape of a hook. }\end{array}$ \\
\hline $\begin{array}{l}6 \text { Just light makeup. It matches with neat } \\
\text { makeup. }\end{array}$ \\
\hline $\begin{array}{l}7 \text { With a bit eyebrow and eyelines, some nude } \\
\text { eyeshadow, and a bit highlighter then you can } \\
\text { use it. }\end{array}$ \\
\hline
\end{tabular}

$\mathrm{Li}$ in this extract explicitly pointed out the target customer-girls who have fair skin (unit 1) as fair ladies do. Then he further gave very specific recommendations (instructions) on how to use the lipstick, including the shape and color of "eyeshadow", "eyelines" and "highlighters" (unit 7), which greatly help girls find appropriate makeup set in a very effective and efficient way. Potential customers who are inexperienced in doing makeups or too busy to think over what type of makeup suits the lipstick find Li very helpful. In this sense, Li's role is similar to "more recommendation" that appears on ecommerce platforms (e.g., Amazong and Tmall) when consumers place an order.

\section{Contextualization.}

\#11 Extract

\begin{tabular}{|l|}
\hline \multicolumn{1}{|c|}{ Spoken Texts } \\
\hline $\begin{array}{l}\text { 1 Summer is coming. It will be windy. Really, if } \\
\text { you buy this matte lipstick, you hair won't get } \\
\text { stuck on your lips. }\end{array}$ \\
\hline $\begin{array}{l}2 \text { Pretties, if you go on business trips, or go } \\
\text { abroad, please buy this one. }\end{array}$ \\
\hline Isn't it beautiful? It is a color for daily use.
\end{tabular}

In these three short extracts, Li enumerated four different circumstances - "in summer" (unit 1), "business trips" (unit 2), going "abroad" (unit 2), and "daily" life (unit $3)$. Such contextualization - "framing a message in a context meaningful to the recipient with the use of contextual variables" (Maslowska, Smit \& van den Putte, 2016), comprises an effective persuasion strategy in the era of internet and social media as people are more often than not overwhelmed by the ocean of information and thus find it challenging to make a decision when shopping. First, by concretely specifying the occasions for different lipsticks, Li, personalized potential customers by imagining their lifestyles and saved the troubles for them who are not adept at or do not have time to 
choose appropriate cosmetics for different occasions. In this sense, he is an human artificial intelligence. Second, these contextualized messages contain personal cues that audiences might identify with. That is, Li evoked the similarities between the message he uttered and its recipients, and thus enhanced audiences' self-referencing and increased their motivation for social commerce (Aaker, Brumbaugh \& Grier 2000; Petty et al. 2009). This personalization strategy, aided by Li's frequent usages of imperatives, can often create artificial needs and foster unnecessary consumptions (Koteyko \& Nerlich, 2007). In other words, audiences are taught "to desire and generate demand for and consuming mass-marketed goods and services" (Cohen, 2008, p.8)

Interactivity.

\#12 Extract

\begin{tabular}{|c|c|}
\hline Spoken Texts & Livestreaming Images \\
\hline $\begin{array}{l}1 \text { Assistant: They are all sending messages asking } \\
\text { which color suits their mother. }\end{array}$ & \\
\hline $2 \mathrm{Li}:$ You want to know which color for your mother? & \\
\hline $\begin{array}{l}3 \text { I will try on some colors for mother in a bit, al- } \\
\text { right? I will show you later. Right now, I am still } \\
\text { choosing colors. (..). I see you your messages asking } \\
\text { which color suits mothers, and want to buy for your } \\
\text { mom. I will tell you later what color mothers like, } \\
\text { ok? Give me some time, I will tell you which color } \\
\text { your mom should buy. }\end{array}$ & \\
\hline 4 I will let you know after I try on all colors. & \\
\hline
\end{tabular}

This conversation between $\mathrm{Li}$ and one of his team members obviously was triggered after seeing messages sent by audiences. Such interactivity, represents one of the most salient features of participatory web-WEB 2.0 (Baldauf, Develotte \& Ollagnier-Beldame, 2017). Different from being passive recipients of traditional advertisements, audiences of ecommerce livestreaming are able to communicate their needs and feedback by sending real time comments to interact with live-streamers, $\mathrm{Li}$ in this case, and the livestreaming platform. Li, by selecting and reading out barrages on screen, makes his audiences heard and gives power to audiences. In unit 3, Li kept starring on his second device to read barrages and keep himself updated with audience's demands. The combination use of verbal languages and eye contacts creates the impression for the audience that they are valued and heard. Interactivity in this way foregrounds the role of consumers and construct perceived equality (Shanahan, Tran \& Taylor, 2019). As a consequence, the consumerist nature of traditional selling process is obscured. Rather than merely emphasizing positives of advertised products, ecommerce livestreaming accentuates the needs of consumers through interactivity and makes shopping highly 
personalized. Potential consumers are thus having the feeling that they play a proactive roles in consumption process in this live (social) commerce, as opposed to conventional practice in which they are passive recipients and lured to consumer by capitalists. By attaching social media property to ecommerce, corporations manages to backgraound the notion of consumerism and foregrounds the role of needs of consumers.

\section{Discussion and Conclusion}

In this paper, we analyzed discursive strategies demonstrated in ecommerce livestreaming by concentrating on one illustrative case-ecommerce live-streamer Austin Li. As a male broadcaster, he achieved phenomenal success by selling lipsticks to female users. Intrigued by his achievement, we first examined the socio-economic context for the hyping live commerce and then particularly focused our attention on salient discursive strategies Li adopts. Our analysis suggests that in social media 2.0 era, attention is a valuable asset for microcelebrities (Marwick, 2013) and conducting behaviors that are incongruent to social norms represents one of the strategies that microcelebrities often resort to. In our case, $\mathrm{Li}$ as a male streamer accumulated his fame by promoting and trying on female cosmetic - lipsticks. Such behavior apparent is against Chinese social norm that discourages males using lipsticks, even just for the purpose of work. However, rather than bringing forth harm, using his gender as a resource to accumulate attention proves a successful strategy.

After considering Li's personal peculiarities against current backdrop of attention economy, we then moved to Li's discourse in livestreaming session. From the analysis in previous section we can see that Li's discourse serves two main purposes: building trust and persuade audiences into engaging in online shopping. First, building trust features great important in ecommerce where false information represents one of consumers' biggest concerns (Gefen, Karahanna \& Straub, 2003). There are several ways to construct trust, including benevolence, competence and integrity (Gibbson \&Manuel, 2003). In Li's case, he constructs his credibility through showing his integrity and impartiality via explicitly criticizing world famous brand and aligning himself with audiences. His discursive strategy of giving honest reviews and taking stances with audiences makes himself a reliable key opinion leader, which is an important antecedent for him to disseminate information and promote commercial products. Second, when promoting items, Li draws on a range of multimodal resources to fulfill various purposes. In terms of linguistic forms, he uses exclamations, imperatives and rhetorical devices (i.e., metaphors and similes), direct address with second pronoun you, celebrity endorsement to attract audience's attention, create equality, satisfy audience's desire for fancy life, all of which effectively contribute to maximizing persuasiveness (Cockcroft \& Cockcroft, 2013). With regards to non-linguistic semiosis, we identify that gestures, facial expressions, sounds and volumes comprise important resources to complement the persuasive power of language. Those strategies identified here are no rare to conventional advertising discourses. Beside them, in this study we found that unctions and features particular to ecommerce livestreaming provides Li news ways to disseminate his persuasiveness. The salient affordances of ecommerce livestreaming platforms 
consist of their delimitation of time, real-time interactivity, and video-aided communication. Aided by these affordances, $\mathrm{Li}$ is able to spend more time on personalizing and interacting with his audiences. For instance, $\mathrm{Li}$ often enumerates represented groups and specific contexts for using certain products in his livestreaming sessions. By selecting, reading out and constantly looking at audience's barrages sent, $\mathrm{Li}$ interacts with and further gives power to his audiences.

\section{References}

1. Aaker, J. L., Brumbaugh, A. M., \& Grier, S. A. Nontarget markets and viewer distinctiveness: The impact of target marketing on advertising attitudes. Journal of Consumer Psychology, 9(3), 127-140 (2000).

2. Azam, A., Qiang, F., \& Sharif, S. Personality based psychological antecedents of consumers' trust in e-commerce. Journal of WEI business and economics, 2(1), 31-40 (2013).

3. Baldauf, H., Develotte, C., \& Ollagnier-Beldame, M. The effects of social media on the dynamics of identity: Discourse, interaction and digital traces. Alsic. Apprentissage des Langues et Systèmes d'Information et de Communication, 20(1) (2017).

4. Baykal, N. Multimodal construction of female looks: An analysis of mascara Advertisements. Dilbilim Araştırmaları Dergisi, 27(2), 39-59 (2016).

5. Blommaert, J. Discourse: A critical introduction. Cambridge University Press, Cambridge (2005).

6. Bondi, M. The future in reports: Prediction, commitment and legitimization in corporate social responsibility. Pragmatics and Society, 7(1), 57-81 (2016).

7. Brady, Chris K. A Multimodal Discourse Analysis of Female K-pop Music Videos. Master's Thesis. University of Birmingham, Birmingham (2015).

8. Cao, X. Bullet Screens (Danmu): Texting, Online Streaming, and the Spectacle of Social Inequality on Chinese Social Networks. Theory, Culture \& Society, 0(0), 1-21 (2019).

9. CBNData. 2020 New Economy Report on Taobao Livestreaming, https://www.cbndata.com/report/2219/detail?isReading=report\&page=1, last accessed 2020/06/08.

10. Chandon, P., Hutchinson, J. W., Bradlow, E. T., \& Young, S. H. Does in-store marketing work? Effects of the number and position of shelf facings on brand attention and evaluation at the point of purchase. Journal of Marketing, 73(6), 1-17 (2009).

11. Cockcroft, R., \& Cockcroft, S. Persuading people: An introduction to Rhetoric. Macmillan International Higher Education (2013).

12. Cohen, N. The valorization of surveillance: Towards a political economy of Facebook. Democratic Communiqé, 22 (1), 5-22 (2008).

13. Dressler, R.A., Kreuz, R.J., Transcribing oral discourse: a survey and a model system. Discourse Process. 29 (1), 25-36 (2000).

14. Fairclough, N. Language and Power. Pearson Education, Essex (2001).

15. Frey, L. R., Botan, C. H., \& Kreps, G. L. Investigating communication: An introduction to Research Methods. Pearson, Boston (1999).

16. Fuoli, M. Building a trustworthy corporate identity: A corpus-based analysis of stance in annual and corporate social responsibility reports. Applied Linguistics, 39(6), 846-885 (2018).

17. Fuoli, M., \& Hart, C. Trust-building strategies in corporate discourse: An experimental study. Discourse \& Society, 29(5), 514-552 (2018). 
18. Fuoli, M., \& Paradis, C. A model of trust-repair discourse. Journal of Pragmatics, 74, 52-69 (2014).

19. Fung, A. Faye and the Fandom of a Chinese Diva. Popular Communication, 7(4), 252-266 (2009).

20. Gamson, J. The unwatched life is not worth living: The elevation of the ordinary in celebrity culture. PMLA, 126(4), 1061-1069 (2011).

21. Gefen, D., Karahanna, E., \& Straub, D. W. Trust and TAM in online shopping: An integrated model. MIS quarterly, 27(1), 51-90 (2003).

22. Gibson, C. B., \& Manuel, J. A. Building Trust: Effective Multicultural Communication Processes in Virtual Teams. In Gibson, C. B., Cohen, S. G. (Eds.), Virtual Teams That Work, Creating Condition for Virtual Team Effectiveness, pp. 59-89. Jossey, Bass (2003).

23. Gill, Sulveen K. A Multimodal Analysis of cover Stories on Mobile Phones: An Ideational Perspective. Research report. Kuala Lumpur: Universiti of Malaya (2015).

24. Goddard, A. The Language of Advertising: Written Texts. Psychology Press, London (2002).

25. Halliday, M. A. K. Language as a Social Semiotic.Edward Arnold, London (1978)

26. Halliday, M. A. K. An Introduction to Functional Grammar. Longman, London (1994).

27. Hajli, N., Sims, J., Zadeh, A. H., \& Richard, M. O. A social commerce investigation of the role of trust in a social networking site on purchase intentions. Journal of Business Research, 71, 133-141 (2017).

28. Hart, C. Discourse, Grammar and Ideology: Functional and Cognitive Perspectives. Bloomsbury Publishing, (2014).

29. Hidalgo-Downing \& Kraljevic-Mujic. Metaphor and persuasion in commercial advertisement. In Semino, E., \& Demjén, Z. (Eds.). The Routledge Handbook of Metaphor and Language, pp. 323-336. Taylor \& Francis, Oxon \& New York (2017).

30. Hu, C., \& Luo, M. A Multimodal Discourse Analysis of Tmall's Double Eleven Advertisement. English Language Teaching, 9(8), 156-169 (2016).

31. iFeng Finance. Cover: Talk with Lipstick King Austin Li [video file], https://www.iqiyi.com/v_19rv8wfv8o.html, last accessed 2020/06/10.

32. iiMedia Research. Statistical Analysis and Trends of Ecommerce Livestreaming Industryin China (2020-2021), http://www.jhsbggw.com/zhibo/970.html, last accessed 2020/06/10.

33. iiMedia Research. Statistics of Livestreaming: Taobao Livestreaming Platform Boasts 20,000 Hosts in 2019, https://www.iimedia.cn/c1061/69517.html, last accessed 2020/06/10.

34. Janiszewski, C., Kuo, A., \& Tavassoli, N. T. The influence of selective attention and inattention to products on subsequent choice. Journal of Consumer Research, 39(6), 1258-1274 (2013).

35. Jerslev, A. In the time of the microcelebrity: Celebrification and the YouTuber Zoella. International Journal of Communication, 10, 5233-5251 (2016).

36. Jewitt, C. The Routledge Handbook of Multimodal Analysis. Routledge, London (2009).

37. Kaur, K., Arumugam, N., \& Yunus, N. M. Beauty product advertisements: A critical discourse analysis. Asian Social Science, 9(3), 61-71 (2013).

38. Koteyko, N., \& Nerlich, B. Multimodal discourse analysis of probiotic web advertising. The International Journal of Language, Society and Culture, 23, 20-31 (2007).

39. Kress, G. Multimodality: A Social Semiotic Approach to Contemporary Communication. Routledge, London (2010).

40. Kress, G. R., \& Van Leeuwen, T. Reading images: The Grammar of Visual Design. Psychology Press, (1996).

41. Kress, G. \& Van Leeuwen, T. Multimodal Discourse: The Modes and Media of Contemporary Communication. Arnold, London (2001). 
42. Labrador, B., Ramón, N., Alaiz-Moretón, H., \& Sanjurjo-González, H. Rhetorical structure and persuasive language in the subgenre of online advertisements. English for Specific Purposes, 34, 38-47 (2014).

43. Li, A. K. (2019). Papi Jiang and Microcelebrity in China: A Multilevel Analysis. International Journal of Communication, 13(0), 3016-3034 (2019).

44. Literat, I., Conover, A., Herbert-Wasson, E., Kirsch Page, K., Riina-Ferrie, J., Stephens, R., ... \& Vasudevan, L. Toward multimodal inquiry: opportunities, challenges and implications of multimodality for research and scholarship. Higher Education Research \& Development, 37(3), 565-578 (2018).

45. Machin, D., \& Mayr, A. How to Do Critical Discourse Analysis: A Multimodal Introduction. Sage, London (2012).

46. Marwick, A. E. Status update: Celebrity, Publicity, and Branding in the Social Media Age. Yale University Press, New Haven (2013).

47. Marwick, A. E. Instafame: Luxury selfies in the attention economy. Public culture, 27(75), 137-160 (2015).

48. Maslowska, E., Smit, E. G., \& van den Putte, B. It is all in the name: A study of consumers' responses to personalized communication. Journal of Interactive Advertising, 16(1), 74-85 (2016).

49. Mayer, R. C., Davis, J. H., \& Schoorman, F. D. An integrative model of organizational trust. Academy of Management Review, 20(3), 709-734 (1995).

50. Meyer, C. B. A case in case study methodology. Field Methods, 13(4), 329-352 (2001).

51. Petty, R. E., Priester, J. R, \& Briñol, P. Mass media attitude change: Implications of the elaboration likelihood model of persuasion. In J. Bryant \& D. Zillmann (Eds.), LEA's communication series. Media effects: Advances in Theory and Research, pp. 155-198. Lawrence Erlbaum Associates Publishers, (2002).

52. Recktenwald, D. Toward a transcription and analysis of live streaming on Twitch. Journal of Pragmatics, 115, 68-81 (2017).

53. Recktenwald, D. The discourse of online live streaming on twitch: communication between conversation and commentary (Doctoral dissertation, The Hong Kong Polytechnic University) (2018)

54. Ringrow, H. The Language of Cosmetics Advertising. Springer, London (2016).

55. Romaniuk, J., \& Nguyen, C. Is consumer psychology research ready for today's attention economy?. Journal of Marketing Management, 33(11-12), 909-916 (2017).

56. Semino, E. Metaphor in Discourse. Cambridge University Press, Cambridge (2008).

57. Shanahan, T., Tran, T. P., \& Taylor, E. C. Getting to know you: Social media personalization as a means of enhancing brand loyalty and perceived quality. Journal of Retailing and Consumer Services, 47, 57-65 (2019).

58. Sharma, S., Menard, P., \& Mutchler, L. A. Who to trust? Applying trust to social commerce. Journal of Computer Information Systems, 59(1), 32-42 (2019).

59. Sinclair, J. Trust the Text: Language, Corpus and Discourse. Routledge, London (2004).

60. Sinolink Securities. Analytical Report on Ecommerce Livestreaming of Microcelebrities, http://www.767stock.com/2019/12/12/49335.html, last accessed from 2020/06/12.

61. Sobrino, P. P. Multimodal metaphor and metonymy in advertising. John Benjamins Publishing Company, Amsterdam/Philadelphia (2017).

62. Syakur, A. A., \& Sukri, M. Text of cigarette advertisement: A semiology study of Roland Barthes. International Journal of Linguistics, Literature and Culture, 4(3), 72-79 (2018).

63. Tehseem, T., \& Kalsoom, U. Exploring the veiled ideology in cosmetics adverts: A feminist perspective. European Journal of Research in Social Sciences, 3(2), 81-98 (2015). 
64. Tikhomirova, A., \& Shuai, C. Assessment of trust building mechanisms of e-commerce: a discourse analysis approach. Professional Discourse \& Communication, 1(4), 23-32 (2019).

65. Topklout. (2020). China's MCN Industry White Book, https://www.ershicimi.com/p/5d5291c8ecfcd54aa1f4f5681f7ee74d, last accessed 2020/06/10.

66. Tufekci, Z. "Not this one" social movements, the attention economy, and microcelebrity networked activism. American Behavioral Scientist, 57(7), 848-870 (2013).

67. Van Leeuwen, T. Introducing Social Semiotics. Psychology Press, (2005).

68. Walther, J. B., \& Jang, J. W. Communication processes in participatory websites. Journal of Computer-Mediated Communication, 18(1), 2-15 (2012).

69. Wodak, R. (Ed.). Language, Power and Ideology: Studies in Political Discourse. John Benjamins Publishing Company, Amsterdam/Philadelphia (1989).

70. Yoon, S. J. The antecedents and consequences of trust in online-purchase decisions. Journal of Interactive Marketing, 16(2), 47-63 (2002).

71. Yoon, H. S., \& Occeña, L. G. Influencing factors of trust in consumer-to-consumer electronic commerce with gender and age. International Journal of Information Management, 35(3), 352-363 (2015).

72. Zjakic, H., Han, C., \& Liu, X. "Get fit!"-The use of imperatives in Australian English gym advertisements on Facebook. Discourse, Context \& Media, 16, 12-21 (2017).

\section{Appendix}

Transcription Conventions

Symbol Meaning

TEXT Emphasis or higher volume

Falling final intonation

? Rising final intonation

: $\quad$ Elongated vowel sounds

\{\}$\quad$ Physical actions by the streamer

(..) Brief pauses

[] Overlap in Speech

... Abridged content 